\title{
General Psychiatry Psychosocial treatments for schizophrenia: insights from Russian theoretical psychology
}

\author{
Natalia Semenova (iD) ${ }^{1,2}$
}

To cite: Semenova N. Psychosocial treatments for schizophrenia: insights from Russian theoretical psychology. General Psychiatry 2020;33:e100234. doi:10.1136/ gpsych-2020-100234

Received 31 March 2020 Revised 28 June 2020 Accepted 02 July 2020
Check for updates

(C) Author(s) (or their employer(s)) 2020. Re-use permitted under CC BY-NC. No commercial re-use. See rights and permissions. Published by BMJ.

${ }^{1}$ Laboratory of Psychological Counseling and Psychotherapy, Moscow Research Institute of Psychiatry, Moscow, Russian Federation

${ }^{2}$ Psychosocial Faculty, Pirogov Russian National Research Medical University Medical Faculty, Moscow, Russian Federation

Correspondence to Dr Natalia Semenova; niyami2020@gmail.com

\section{INTRODUCTION}

While the biological approach remained at the forefront in Russian/Soviet psychiatry, several valuable theoretical approaches were developed in Russian/Soviet psychology. This development, however, did not cross the border of the psychiatric domain. The clinical implications of these psychological constructs for the psychosocial treatment of severe mental illness (SMI) were overlooked.

In this article, I shall focus on psychosocial treatments for schizophrenia and explore how the corresponding data aligns with theoretical concepts developed by Lev Vygotsky and Aleksei Leontiev. In addition, I shall briefly describe the theoretical underpinnings of general Russian/Soviet approaches to the treatment of the mentally ill.

\section{THEORETICAL UNDERPINNINGS OF RUSSIAN/ SOVIET APPROACHES TO THE TREATMENT OF THE MENTALLY ILL}

During most of the Soviet era, the biological approach strongly dominated Russian psychiatry. Psychological approaches to the treatment of the mentally ill were primarily based on the ideas of Pavlov and Marx. The treatment was mostly of the directive type (ie, discrete symptoms or problems were addressed in a highly structured, systematic and narrowly focused way). Group psychotherapy was developed on the basis of the principles of Soviet pedagogical science, in particular, of the Soviet educationalist Makarenko ${ }^{1}$ and reflected the dominant collectivist idea of a person being a function of the collective.

The situation changed during the last few decades under the increased influence of Western thought. In line with the results of recent meta-analyses demonstrating evidence for the effects of psychosocial treatments in schizophrenia, ${ }^{2-5}$ the overall approach has become balanced, and one can no longer insist on neuroleptic therapy alone.

In parallel development, a conceptual change occurred in the organisation of Russian psychiatry, which resulted in a departure from the hospital-centred approach towards deinstitutionalisation and a communityoriented model of care. ${ }^{6}$ From this point of view, the psychiatric hospital becomes a link in a 'rehabilitation chain' reaching far into the community. Psychosocial treatments and interventions play an essential role in this rehabilitation programme, complementing pharmacological and other biological interventions. The psychosocial rehabilitation system for patients with a mental illness is based on four traditional and potentially useful modalities: individual, group, family therapy and community support. It includes a combination of components of psychosocial strategies such as psychoeducation, social therapeutic strategies, social support networks, social skills training, cognitive behavioural therapy, and cognitive remediation therapy. The further development and implementation of evidence-based treatments is one of the high-priority areas that needs to be addressed.

\section{THE MEANING OF PSYCHOSOCIAL TREATMENTS ACCORDING TO LEV VYGOTSKY}

Lev Vygotsky (1896-1934) is known for his cultural-historical approach focused on exploring the phenomenon of cultural mediation. ${ }^{7}$ One of the principal concepts introduced by Vygotsky in the psychology of learning was the idea of the zone of proximal development (ZPD). This term is one of the most widely recognised and well-known concepts associated with Vygotsky's scientific work. ${ }^{8}$ Vygotsky defined ZPD as 'the distance between the actual developmental level as determined by independent problem solving 

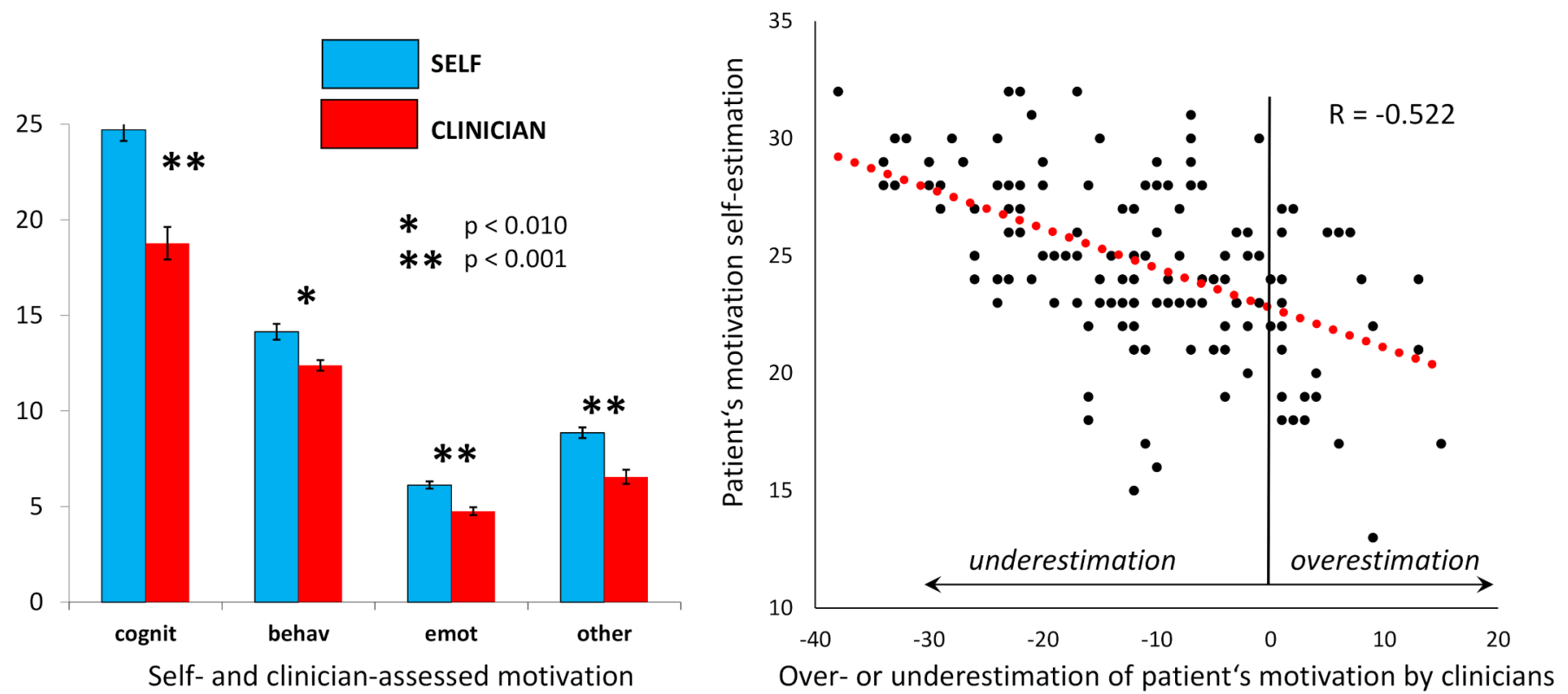

Figure 1 Assessment of chronic schizophrenic patients' motivation by their clinicians and by patients themselves.

and the level of potential development as determined through problem solving under adult guidance or in collaboration with more capable peers'.7

From our point of view, the ZPD concept provides a useful framework for exploring potentially unknown sources of motivation in a patient (as well as the patient's preferences and priorities).

The patient's motivation in the process of treatment is the core determinant of the outcome. Assessment of the motivation is, therefore, the first consequential step in shaping the kinds of psychosocial interventions we offer. In our recent cross-sectional study, we investigated the extent to which clinicians' opinion about patients' motivation corresponded to the patients' self-evaluation.

This study uses a number of measuring instruments including the Apathy Evaluation Scale. ${ }^{9}$ There is a patientside version as well as a therapist-side version of this scale, with an equal number of items in each. Several co-variables (such as age, gender, social functioning, impairments and behavioural problems) were also included. A total of 35 clinicians and 151 patients with schizophrenia spectrum disorders agreed to participate.

The main results of the study are presented in figure 1. Left panel: highly significant differences in each of the four motivation domains (cognitive, behavioral, emotional, and other). Right panel: The vertical axis is a patient's self-assessment of his/her motivation, the horizontal axis is underestimated by the clinician. Each point represents one patient. Solid vertical line corresponds to the equal assessment of motivation by the patient and the clinicians. The points right from this line $(\mathrm{N}=24)$ indicate clinicians' overestimation of patients' motivation. The points left from the line $(\mathrm{N}=125)$ indicate clinicians' underestimation.

The data clearly indicate a strong disparity between the patients' and clinicians' reports. The patients rated themselves as having higher levels of motivation than the levels assigned by their doctors. This hinted at the clinicians' inability to understand the patients' perspective. Furthermore, the more positive the item was, the more likely it was for the clinician to attribute lower scores to the patients' motivation compared with the patients themselves; of note, a reverse relationship was found for negative items.

Previous studies have suggested that clinicians have to be aware that patients with mental illness generally have a different view of their motivation for engaging in treatment than the clinician can estimate or judge, regardless of the framework that is used to measure motivation. ${ }^{10}$ Thus, regarding the question of who should perform the assessment, the previous studies have indicated that the view of neither the patient nor the clinician is sufficient; it is necessary to take both perspectives into account. It is likely that the perceptions are complementary and that only an integrated view would meet clinical reality.

Our hypothesis is that the patient's perspective is most predictive of treatment outcomes. From our point of view, the patient's report can be taken as a 'reference' to be compared with the clinician's perspective. Such an approach may help to increase the probability that interventions are tailored to the patient's perspective, which, in turn, would increase the likelihood of the treatment's success.

We assume that these results are closely related to Vygotsky's ZPD idea. The state of a patient's motivation to be engaged in the therapy is not a dimensionless point, but rather a zone including both the opportunities for progress and the possibilities of a backlash. An interaction with a paternalistic clinician may impede the patient's growth, putting him/her behind their actual level. In contrast, an interaction with a challenging clinician may have the opposite effect, that is, moving him/ 
her ahead of their actual level. To paraphrase Vygotsky's formulation, the ZPD of a patient can be described as the distance between the actual level as determined by independent problem solving and the level of potential development as determined through problem solving under the clinician's guidance or in collaboration with more capable peers.

As for more capable peers - these are patients who become peer leaders within the group format of psychosocial treatments. They become real-life symbols of hope for beginners who are struggling for ways to live productively and become the people they would like to be.

Therefore, effective mental health interventions require a new look at the patients' motivational condition, not as a static 'position' (measured by their self-assessment or the assessment by their clinicians) but rather as a dynamic system of potentially positive and negative forces determining the patients' proximal development.

\section{THE MEANING OF ACTIVITY IN THE WORKS OF ALEKSEI LEONTIEV}

Therapeutic meaning of work activities and work therapy-as the major element of psychosocial treatment approach to SMI-will be discussed in light of studies initiated by the prominent Soviet-Russian psychologist Aleksei Leontiev (1903-1979), with a focus on the activitytheoretical understanding of human behaviour in the historical context of cultural and societal transformation.

Leontiev's research ${ }^{11-13}$ is based on a thorough analysis of the phenomenon of activity. When he initiated his work, activity in psychology was primarily regarded as a set of responses to external stimuli by a passive subject determined through her innate organisation and training. Leontiev considered the activity as a multilevel system. The highest, most general level is activity inspired by motives. More immediate actions and goals associated with them constitute the intermediate level. The lowest level is the level of operations that serve as a means for achieving higher-order goals.

Furthermore, Leontiev indicated that a critical analysis of function and meaning of working activity cannot be confined to the position of work within the traditional means-to-end rationality but needs the perspective of value rationality. For Leontiev, 'activity' consisted of those processes 'that realise a person's actual life in the objective world by which he is surrounded, his social being in all the richness and variety of its forms'. ${ }^{11}$

Having spent much of my career working with patients with schizophrenia, I have always been conscious of Leontiev's ideas, especially as I was developing the concept of psychosocial treatment ingredients.

The recently developed 'place-train' paradigm is particularly relevant to Leontiev's ideas. In the traditional 'trainplace' paradigm, patients are trained to manage their mental symptoms and dysfunctions before they are placed in a real-world environment. They are thoroughly trained in a range of skills enabling them to cope with real-world demands before confronting these challenges on the street. Instead, the 'place-train' paradigm promotes rapid placement within real-world circumstances, followed by in vivo support, resources and training that can help the person remain in those settings successfully. Being placed in a real-world situation, people with psychiatric disorders can experience both the benefits and challenges of this situation. In the course of dealing with reality, they receive all the training and support needed for coping with challenges.

According to Leontiev, activity is a unit of life, mediated by mental reflection that gives the subject a precise orientation in the objective world. In other words, activity is not a set of responses but a system with its own structure, internal transitions and transformations, and its own peculiar development. ${ }^{12}$

In this sense, Leontiev's theory was much ahead of his time. Presently, it is well realised that participation in activity is central to the very definition of recovery in patients with SMI. ${ }^{14}$ Jolley et $a l^{15}$ have recently developed the 'time use construct' and 'time use survey', ${ }^{16} 17$ bearing in mind the categories of activity (work, education, voluntary work, housework and childcare, leisure, sports and hobbies) as well as the lists of activities provided for each category (eg, leisure activities include going to the cinema, pub, eating out). They have shown that patients with schizophrenia spend significantly less time in structured activity than non-clinical groups. ${ }^{18}$ Moreover, activity level can be lowered in individuals at the transition to psychosis. Therefore, monitoring the activity level in individuals at risk of schizophrenia is extremely important from a preventive point of view. Such individuals should receive help in order to maintain their engagement in structured activity and social relationships, which can preclude the onset of SMI.

To summarise, although the traditional Soviet psychiatry merely followed, sometimes with considerable delay, the line of development of Western psychiatry, Soviet psychology managed to produce certain seminal ideas whose importance for a clinical approach to SMI was realised only several decades later. The ideas of Lev Vygotsky offered a perspective to view the patient's recovery as a dynamic system characterised by a particular zone of proximal development. According to the concepts of Alexei Leontiev, the mechanism of this development is related to the involvement of patients in productive activity. Therefore, participation in such an activity is not only a secondary consequence of successful therapy but also an important mediating factor of therapeutic success.

In discussing the application of this theoretical psychology in Russia for the patients with schizophrenia, we deal with the transposition of results from basic research to therapeutic action. From the standpoint of philosophy of science, this is a controversial issue, which becomes even more complicated when empirical knowledge is insufficient. The Soviet Russia context did not appear to be a factor in the development of the psychosocial interventions. At the same time, in today's Russia, 
there is a strong demand for psychosocial methods that are applicable and effective in clinical practice.

Contributors The author conceived of and wrote this editorial.

Funding The author has not declared a specific grant for this research from any funding agency in the public, commercial or not-for-profit sectors.

Competing interests None declared.

Patient consent for publication Not required.

Provenance and peer review Not commissioned; externally peer reviewed.

Open access This is an open access article distributed in accordance with the Creative Commons Attribution Non Commercial (CC BY-NC 4.0) license, which permits others to distribute, remix, adapt, build upon this work non-commercially, and license their derivative works on different terms, provided the original work is properly cited, appropriate credit is given, any changes made indicated, and the use is non-commercial. See: http://creativecommons.org/licenses/by-nc/4.0/.

ORCID iD

Natalia Semenova http://orcid.org/0000-0001-7698-1018

\section{REFERENCES}

1 Makarenko AS. Problems of Soviet school education. Moscow: Progress Publishers, 1951. https://www.marxists.org/reference/ archive/makarenko/works/problems-soviet-school-education.pdf

2 Pitschel-Walz G, Leucht S, Bäuml J, et al. The effect of family interventions on relapse and rehospitalization in schizophrenia--a meta-analysis. Schizophr Bull 2001;27:73-92.

3 De Silva MJ, Cooper S, Li HL, et al. Effect of psychosocial interventions on social functioning in depression and schizophrenia: meta-analysis. Br J Psychiatry 2013;202:253-60.

4 Fusar-Poli P, Papanastasiou E, Stahl D, et al. Treatments of negative symptoms in schizophrenia: meta-analysis of 168 randomized placebo-controlled trials. Schizophr Bull 2015;41:892-9.
5 Velthorst E, Koeter M, van der Gaag M, et al. Adapted cognitivebehavioural therapy required for targeting negative symptoms in schizophrenia: meta-analysis and meta-regression. Psychol Med 2015;45:453-65.

6 Jenkins R, Lancashire S, McDaid D, et al. Mental health reform in the Russian Federation: an integrated approach to achieve social inclusion and recovery. Bull World Health Organ 2007;85:858-66.

7 Vygotsky LS. Mind in society: the development of higher psychological processes. 86. Cambridge, MA: Harvard University Press, 1978.

8 RvD V, Valsiner J. Understanding Vygotsky: a quest for synthesis. Blackwell: Oxford, 1991.

9 Marin RS, Biedrzycki RC, Firinciogullari S. Reliability and validity of the apathy evaluation scale. Psychiatry Res 1991;38:143-62.

10 Jochems EC, van Dam A, Duivenvoorden HJ, et al. Different perspectives of clinicians and patients with severe mental illness on motivation for treatment. Clin Psychol Psychother 2016;23:438-51.

11 Leontiev AN. Activity and consciousness. In: Daglish R, ed. Philosophy in the USSR, problems of Dialectical Materialism. Moscow: Progress Publishers, 1977: 8. http://www.marxists.org/ archive/leontev/works/1977/leon1977.htm

12 Leontiev AN. Problems of the development of mind (Trans. M. Kopylova). Moscow: Progress Publishers, 1981.

13 Leontiev AA. The life and creative path of A.N. Leontiev. J Russ East Europ Psychol 2005;43:8-69.

14 Windell D, Norman R, Malla AK. The personal meaning of recovery among individuals treated for a first episode of psychosis. Psychiatr Serv 2012;63:548-53.

15 Jolley S, Garety PA, Ellett L, et al. A validation of a new measure of activity in psychosis. Schizophr Res 2006;85:288-95.

16 Short S. Review of the UK 2000 time use survey. London: Office for National Statistics, 2006.

17 Lader D, Short S, Gershuny J. The time use survey 2005. London: Office for National Statistics, 2006.

18 Hodgekins J, French P, Birchwood M, et al. Comparing time use in individuals at different stages of psychosis and a non-clinical comparison group. Schizophr Res 2015;161:188-93.

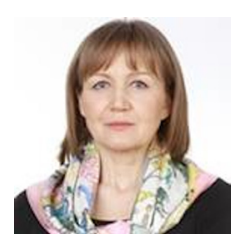

Natalia Semenova obtained a Master's degree from the Department of Psychology at Moscow State University in Russia in 1983, and a PhD degree in Clinical Psychology from Moscow State University in Russia in 1989. She is currently an associate professor and working as the acting chair at the Laboratory of Psychological Counseling and Psychotherapy, a branch of V. Serbsky National Medical Research Centre for Psychiatry and Narcology in Russia. She is also a co-chair at Women's Mental Health Section - World Psychiatric Association, an Associate Fellow of Women's Mental Health Section - Russian Society of Psychiatrists and an international consultant for the International Committee for Morita Therapy (ICMT). Her main research interests include psychosocial treatments in psychiatry, recovery from mental illness, and gender-sensitive care. 